\title{
Ethibond suture in uterus: an unusual cause for secondary sterility
}

\author{
Rajendra kumar Diwakar ${ }^{1 *}$, Meena Naik ${ }^{2}$ \\ ${ }^{1}$ Department of Radio-diagnosis, C.M.Medical College \& Hospital, Kachandur, Durg (CG) 490024, India \\ ${ }^{2}$ Department of Obstetrics and Gynecology, C.M. Medical College \& Hospital, Kachandur, Durg (CG) 490024, India
}

Received: 06 August 2015

Revised: 12 September 2015

Accepted: 01 November 2015

\section{*Correspondence: \\ Dr. Rajendra kumar Diwakar, \\ E-mail: rkdiwakar49@yahoo.co.in}

Copyright: ( $\odot$ the author(s), publisher and licensee Medip Academy. This is an open-access article distributed under the terms of the Creative Commons Attribution Non-Commercial License, which permits unrestricted non-commercial use, distribution, and reproduction in any medium, provided the original work is properly cited.

\begin{abstract}
Failure to conceive two years after the LSCS, the patient was being investigated. Hysteroscopy revealed the presence of Ethibond suture in the uterine cavity attached to the lower part of the previous LSCS scar. The presence of this foreign body was acting as an intra-uterine contraceptive device responsible for failure of contraception. The presence of foreign body in the uterus such as bone pieces left after previous abortion, presence of suture of cervical circlage etc. have been reported. But the presence of Ethibond suture in the uterine cavity resulting in secondary sterility is being reported for the first time.
\end{abstract}

Keywords: Secondary sterility, Contraception, Ethibond suture, Foreign body in uterus, Cervical circlage suture in uterus

\section{INTRODUCTION}

The presence of foreign bodies such as fetal bones, forgotten IUCD, cervical circlage suture, gauze packing etc. have been reported in the literature acting as IUCD. It is extremely unusual to find the presence of an unabsorbable suture material in the uterine cavity during hysteroscopy in a patient being evaluated for secondary infertility post-LSCS. Vicryl or catgut is commonly used as a suturing material for the closure of uterine incision in caesarean section.

\section{CASE REPORT}

A 26 year old female presented to us with a history of secondary infertility for 2.5 years after a caesarean delivery. The usual investigations for infertility such as pelvic ultrasound, hormonal tests and husband semen analysis were already done and found to be normal.
She was para1 live1 with regular menstrual cycles of 3032 days with painful heavy flow for 3-4 days. She had the last menstrual period 5 days back. General physical and systemic examinations were normal. Per vaginal examination revealed that the uterus was normal in size, shape and contour. Uterine cervix was normal. After being counseled for evaluation of uterus and tubes by hysterosalpingography (HSG) or hystero-laparoscopy; she opted for hystero-laparoscopy providing an opportunity for the evaluation and treatment in the same sitting.

Routine laboratory investigations for blood, urinalysis, ECG and X-ray chest were found to be normal. Preanaesthetic check-up and fitness was done and the patient was posted for hysterolaparoscopy on the $8^{\text {th }}$ day of cycle.

Hysteroscopy was done with $4 \mathrm{~mm}$ Bettochi's office hysteroscope. Tablet misoprostol was given $400 \mathrm{mg}$ intravaginally 2 hours before the procedure for cervical softening. The uterine cavity was distended with 
instillation of saline and the endomat was used to maintain the distension inside the uterine cavity.

During hysteroscopy, a coiled suturing material of greenish colour filling the uterine cavity was found (Fig 1). It was tethering to the lower uterine segment and the upper part of cervix on left side from where it was cut and pulled through the grasper. The whole length of ethibond suture came out. There was no rent in the uterus. Laparoscopy with chromotubation was done. The uterus was normal in size and shape and no defect was found in the uterus. Since the end of suture was tethering to the angle of the uterine scar, it could not be expelled. Following the procedure, postoperative period was uneventful and the patient was discharged the next day.

Closure of uterine incision during cesarean section is usually done with an absorbable suture material such as vicryl or catgut. It is possible that during the previous cesarean section, the ethibond suture might have been used for the closure of uterine incision which went in the uterine cavity during involution of the uterus.

\section{DISCUSSION}

Secondary infertility due to the presence of inert foreign body in the uterus such as fetal bones from previous midtrimester abortion; ${ }^{1-3}$ forgotten IUCD,${ }^{4,5}$ the presence of mersiline tape, ${ }^{6}$ gauze packing stitched to the uterine cavity, ${ }^{7}$ or the presence of cervical circlage suture in the uterus $^{8}$ have also been reported in the literature. However, the presence of a full length ethibond suture material in the uterus after previous cesarean section is a rare entity (Figure 1) and has not been reported in the literature.

Hassan SA and Mohd A sbenati reported removal of a meth as part of eraser from cervix of a woman causing infertility and persistent vaginal discharge for 13 years. ${ }^{9}$

Leela KP reported that a cervical cerclage suture retained for 15 years as a cause of secondary infertility and causing abnormal uterine bleeding was removed hysteroscopically. ${ }^{8}$ Other foreign bodies found are broken laminaria tents, tips of curettes, nonabsorbable suture materials. $^{8}$

Çepni et al reported a case of fetal bones neglected in the uterus for 8 years after the termination of a pregnancy. The patient presented with a history of infertility and persistent vaginal discharge. Transvaginal ultrasound detected an intrauterine foreign body. It was found to be fetal bones left inside the uterus after dilatation and curettage. $^{3}$

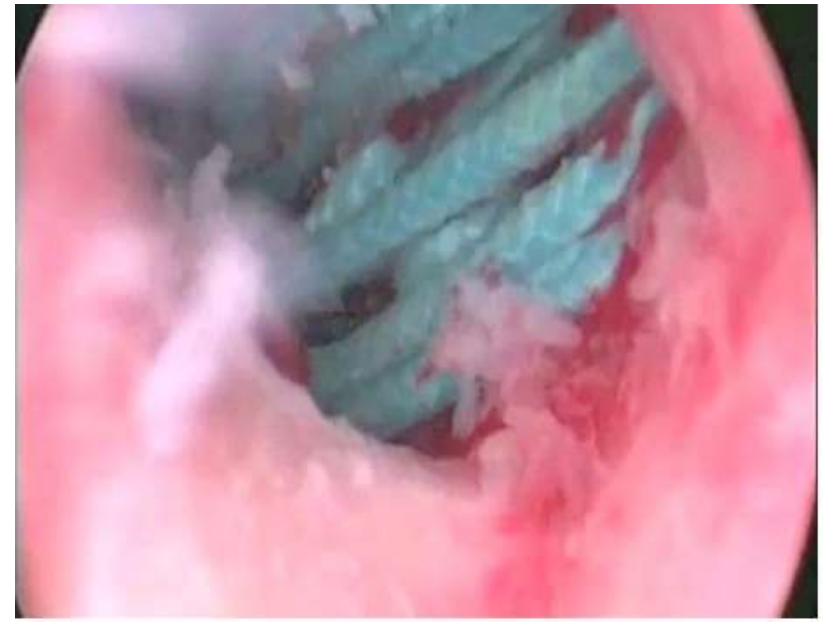

Figure 1: Ethibond suture in the uterus seen during hysteroscopy.

A case has been reported in the Hysteroscopic text book by Linda $\mathrm{D}$. Bradley where the patient presented with discharge per vaginum. ${ }^{6}$ After several blind procedures complaints persisted. The Mersilene tape was removed under the guidance of Hysteroscope. ${ }^{6}$

Bettochi et al reported two cases of hysteroscopic removal of uterocervical gauze packing inadvertently sutured to the uterine cavity in a case of cesarean section after uterine hemorrhage resistant to medical therapy was removed from the uterine cavity. ${ }^{7}$

In our case, the patient was totally asymptomatic except for secondary infertility. Ultrasound did not reveal any foreign body. During hysteroscopy the uterine cavity was filled with the suture material. The patient was unaware of the presence of nonabsorbable suture material having been used in her previous section neither it was there in her records. This emphasizes the need for hysteroscopic evaluation of uterine cavity in cases of infertility since it provides an opportunity for both the diagnostic as well as therapeutic application in the same sitting.

Funding: No funding sources Conflict of interest: None declared Ethical approval: Not Required

\section{REFERENCES}

1. Al-Sunaidi M. Retained fetal bones in-utero causing secondary infertility. Baharain Med Bull. 2011:33(1):47-8.

2. Girish T, Adevemi OA. Viable retained fetal bones and secondary infertility: ultrasound and hysteroscopic appearances. J Obstet Gynaecol. 2003; 23(1):83-4.

3. Cepni I, Kumbak B, Ocal P, Idil M, Aksu F. Infertility due to intrauterine residual fetal bone fragments. J Clin Ultrasound 2004;32:253-5. 
4. Olson RO. The forgotten IUD as a cause of Infertlity. Obs \& Gynecol. 1967;29(4):579-80.

5. Knudsen HJ, RasmussenK. The "forgotten" intrauterine device: a cause of infertility. Arch GynecolObstet.1993;253(3):143-4.

6. Bradley LD, Falcone T. Hysteroscopy: Office Evaluation and Management of the Uterine Cavity. 2009.

7. Bettocchi S, Sardo ADS, Pinto L, Castaldi MA. Journal of Minimally Invasive Gynecol. 2009;16(1):88-91.
8. Leela KP. Cervical Circlage Suture Presenting as Foreign Body Uterus-Case Report. Austin J Clin Case Report. 2014;1(12):1060.

9. Abduljabbar HS, Sbenati MA. Neglected intracervical bizarre foreign object causing infertility. Saudi Med J. 2012;33(12):1343-5.

Cite this article as: Diwakar R, Naik M. Ethibond suture in uterus: an unusual cause for secondary sterility. Int J Reprod Contracept Obstet Gynecol 2015;4:2050-2. 